\title{
Mass movement on Vesta at steep scarps and crater rims
}

\author{
K. Krohn ${ }^{\text {a,* }}$, R. Jaumann ${ }^{\mathrm{a}, \mathrm{b}}$, K. Otto ${ }^{\mathrm{a}}$, T. Hoogenboom ${ }^{\mathrm{c}}$, R. Wagner ${ }^{\mathrm{a}}$, D.L. Buczkowski ${ }^{\mathrm{d}}$, B. Garry ${ }^{\mathrm{e}}$, \\ D.A. Williams ${ }^{\text {f }}$, R.A. Yingst ${ }^{e}$, J. Scully ${ }^{g}$, M.C. De Sanctis ${ }^{h}$, T. Kneissl ${ }^{b}$, N. Schmedemann ${ }^{b}$, E. Kersten ${ }^{\text {a }}$, \\ K. Stephan ${ }^{\text {a }}$, K.-D. Matz ${ }^{\mathrm{a}}$, C.M. Pieters ${ }^{\mathrm{i}}$, F. Preusker ${ }^{\mathrm{a}}$, T. Roatsch ${ }^{\mathrm{a}}$, P. Schenk ${ }^{\mathrm{c}}$, C.T. Russell ${ }^{\mathrm{g}}$, \\ C.A. Raymond ${ }^{\mathrm{j}}$
}

\author{
anstitute of Planetary Research, German Aerospace Center (DLR), 12489 Berlin, Germany \\ ${ }^{\mathrm{b}}$ Freie Universität Berlin, Inst. of Geosciences, Planetology and Remote Sensing, 12249 Berlin, Germany \\ ${ }^{\mathrm{c}}$ Lunar and Planetary Institute, Houston, TX 77058, USA \\ d John Hopkins University Applied Physics Laboratory, Laurel, MD 20723, USA \\ e Planetary Science Institute, Tucson, AZ 85719, USA \\ ${ }^{\mathrm{f}}$ School of Earth and Space Exploration, Arizona State University, Tempe, AZ 85287, USA \\ ${ }^{\mathrm{g}}$ Department of Earth and Space Sciences, University of California, Los Angeles, CA 90095-1567, USA \\ ${ }^{\mathrm{h}}$ National Institute of Astrophysics, 00133 Rome, Italy \\ i Brown University, Providence, RI 02912, USA \\ jJet Propulsion Laboratory, California Institute of Technology, Pasadena, CA 91109, USA
}

\section{A R T I C L E I N F O}

Article history:

Received 30 April 2013

Revised 30 January 2014

Accepted 4 March 2014

Available online $\mathrm{xxxx}$

Keywords:

Asteroid Vesta

Asteroids, surfaces

Geological processes

Impact processes

\begin{abstract}
A B S T R A C T
The Quadrangles Av-11 and Av-12 on Vesta are located at the northern rim of the giant Rheasilvia south polar impact basin. The primary geologic units in Av-11 and Av-12 include material from the Rheasilvia impact basin formation, smooth material and different types of impact crater structures (such as bimodal craters, dark and bright crater ray material and dark ejecta material). Av-11 and Av-12 exhibit almost the full range of mass wasting features observed on Vesta, such as slump blocks, spur-and-gully morphologies and landslides within craters. Processes of collapse, slope instability and seismically triggered events force material to slump down crater walls or scarps and produce landslides or rotational slump blocks. The spur-and-gully morphology that is known to form on Mars is also observed on Vesta; however, on Vesta this morphology formed under dry conditions.
\end{abstract}

(c) 2014 Elsevier Inc. All rights reserved.

\section{Introduction}

In 2007 the Dawn spacecraft was launched into space in order to study the two most massive asteroids of the Solar System: Vesta and Ceres. In July 2011 Dawn arrived at Vesta and started its scientific observations.

To understand the geologic history of Vesta, a global geologic map, at a scale of 1:500,000 (Yingst et al., 2014) and a set of 15 quadrangle maps (Fig. 1) at a scale of $1: 250,000$ in more detail were produced by the Dawn Science Team (Roatsch et al., 2012, 2013; Williams et al., this issue). We mapped the surface of the Quadrangles Av-11 and Av-12 in the southern hemisphere of Vesta.

The surface in this region shows various types of mass wasting features. In the Quadrangles Av-11 and Av-12, a set of different mass wasting features were identified: (1) slump blocks, (2)

\footnotetext{
* Corresponding author.

E-mail address: Katrin.Krohn@dlr.de (K. Krohn).
}

spur-and-gully morphologies on crater rims and (3) landslides in craters.

Observations of other planetary surfaces show similar types of mass wasting features. Examples include slumps, avalanches, debris flows and spur-and-gully morphologies. The formation of such mass wasting features is likely affected by a flowing fluid, such as water, which has been discussed for Mars by Lucchitta et al. (1992) and Malin and Edgett (2000).

On the Moon (Bart, 2007), the Galilean moons Ganymede, Callisto and Europa (Moore et al., 1999), and small bodies, such as Phobos (Shingareva and Kuzmin, 2001) and Lutetia (Massironi et al., 2012), mass wasting processes under dry conditions are observed. Recent studies have shown that the production of spur-and-gully morphologies by dry granular flows is possible. Granular materials can demonstrate a fluid-like behavior and therefore can produce landforms with all of the geomorphic features created by liquid flows (Bart, 2007; Shinbrot et al., 2004; Treiman, 2003). Dry slides or slumps are observed on Ganymede and are also found on very small scales [100-m scales] on Europa 


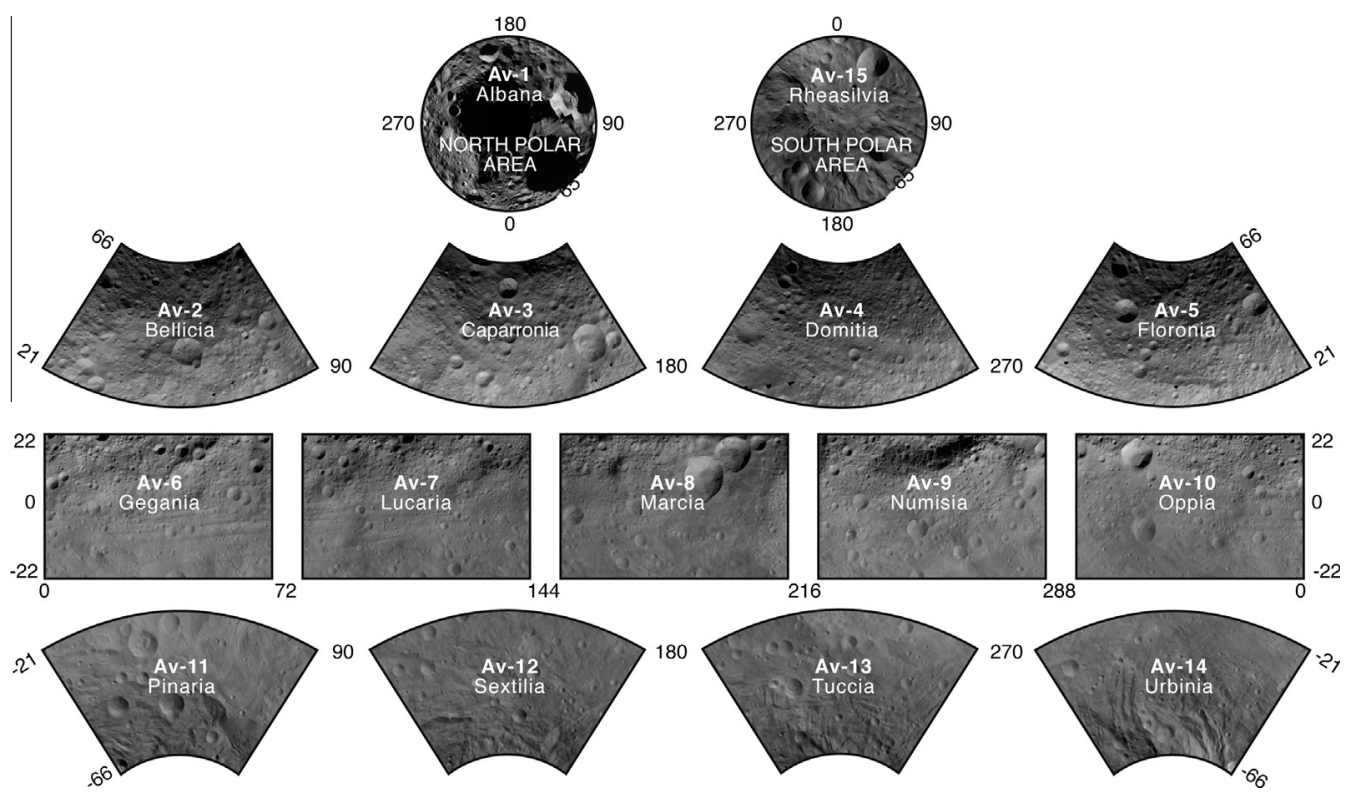

Fig. 1. Vesta map tiles. Av-11 and Av-12 were studied in this paper.

(Moore et al., 1999), along slopes caused by gravity and over steepening. Other mass wasting features can be explained by the influence of seismic waves due to meteorite impacts, such as the inter-crater landslide on Phobos observed by Shingareva and Kuzmin (2001) or on Lutetia (Massironi et al., 2012). Massironi et al. (2012) observed that a large amount of ejecta material on Lutetia was subsequently remobilized by seismic shaking and produced landslides, such as taluses, rock debris, rock-falls, or sliding downslope movements. Callistan debris avalanches, similar to the smaller ones observed on Mars, were also triggered by local impacts or over-steepened slopes (Chuang et al., 1998; Moore et al., 1999).

In this paper we give an overview on the different mass wasting features we found on Vesta and compare them with the features on other bodies. We explain how the mass wasting features could have been formed.

\section{Datasets and methods}

For mapping both quadrangles and the analysis of mass wasting features, Dawn Framing Camera (FC) data (Sierks et al., 2011) and Visible and Infrared Spectrometer (VIR) (De Sanctis et al., 2011) data as well as the digital terrain model (DTM) developed by Preusker et al. (2012) were used. The data processing of the FC images is described in Roatsch et al. (2012,2013). During the orbital phases, the FC and the VIR mapped the surface with image scales of $\sim 260 \mathrm{~m} /$ pixel (FC) and $\sim 700 \mathrm{~m} /$ pixel (VIR) in the Survey phase, $\sim 60 \mathrm{~m} /$ pixel (FC) and $\sim 200 \mathrm{~m} / \mathrm{pixel}$ (VIR) in the High Altitude Mapping Orbit (HAMO) and $\sim 20 \mathrm{~m} /$ pixel (FC) and $\sim 60 \mathrm{~m} /$ pixel (VIR) in the Low Altitude Mapping Orbit (LAMO). The topography of Vesta is derived from the Dawn FC Stereo images (Preusker et al., 2012).

Dawn arrived in the Vestan southern summer, allowing a complete survey of the south polar and equatorial regions with the Survey and HAMO data (Russell et al., 2012). The high resolution LAMO data covers approximately $90 \%$ of the surface of Vesta from $90^{\circ} \mathrm{S}$ up to $55^{\circ} \mathrm{N}$ and approximately $98 \%$ of the Av- 11 and Av-12 quadrangles. To relate the geological and morphological surface and spectral properties, we mapped the distribution of the geological units in Av-11 and Av-12, primarily using the Vesta LAMO data (Fig. 2). The remaining $2 \%$ gaps were mapped with the help of the HAMO (Fig. 3) data.
Vesta was separated into 15 mapping quadrangles (map tiles) based on the Vesta HAMO atlas, which is described by Roatsch et al. (2012). The maps presented use the 'Claudia' system (Roatsch et al., 2012; Russell et al., 2012). At the time of this writing, the PDS is providing Dawn data in a longitude system that can be obtained from the Claudia longitude by subtracting $150^{\circ}$ (Williams et al., this issue).

The complete geological map of Av-11 and Av-12 is displayed on a LAMO mosaic projected in a Lambert conic conformal projection with two standard parallels at $30^{\circ} \mathrm{S}$ and $58^{\circ} \mathrm{S}$ at a scale of 1:250,000 (Roatsch et al., 2012).

The geological mapping of the surface units was performed following the guidelines of Skinner et al. (2003), Wilhelms (1990) and Hansen (2000). The mapping was based on the Digital Cartographic Standard for Geologic Map Symbolization defined by the U.S. Geological Survey (2006) and Nass et al. (2011) and performed using ESRI's software package ArcGIS. The RGB (red, green, blue) color code for the geologic units was defined after the one used in the Vesta global map by Yingst et al. (2014).

A combination of HAMO and LAMO FC data (Figs. 2 and 3), VIR data, photometric data (Fig. 4) and DTM (Fig. 5) and a slope map (Fig. 6) were used to create the final map.

\section{Geologic setting}

Av-12 (also known as Sextilia) is located between 21-66 South latitude and $90-180^{\circ}$ East longitude. This quadrangle is named after the Sextilia crater (lat. $39^{\circ} \mathrm{S}$, long $146^{\circ} \mathrm{E}$ ), which is approximately $20 \mathrm{~km}$ in diameter, displaying a very well preserved rim and ejecta blanket (Krohn et al., 2012a). Av-11 (also known as Pinaria) is located between $21-66^{\circ}$ South latitude and $0-90^{\circ}$ East longitude and is named after the Pinaria crater (lat. $29^{\circ} \mathrm{S}$, long $32^{\circ} \mathrm{E}$ ). The crater is $37 \mathrm{~km}$ in diameter, with a fresh rim and extensive slumped material in its center.

The wide range of topographical features in Quadrangle Av-12 is caused by the two large scarps dominating the quadrangle, Agonium Rupes (108 $\mathrm{km}$ in length, centered at lat. $53.3^{\circ} \mathrm{S}$ and long $166.7^{\circ} \mathrm{E}$ ) and Matronalia Rupes (centered at lat. $49.5^{\circ} \mathrm{S}$ and long $82.7^{\circ} \mathrm{E}$ ), which is $208 \mathrm{~km}$ in length and continues into Quadrangle Av-11 (Krohn et al., 2012a). Matronalia Rupes defines the eastern rim of the Rheasilvia impact crater (Jaumann et al., 2012) (Fig. 7). 


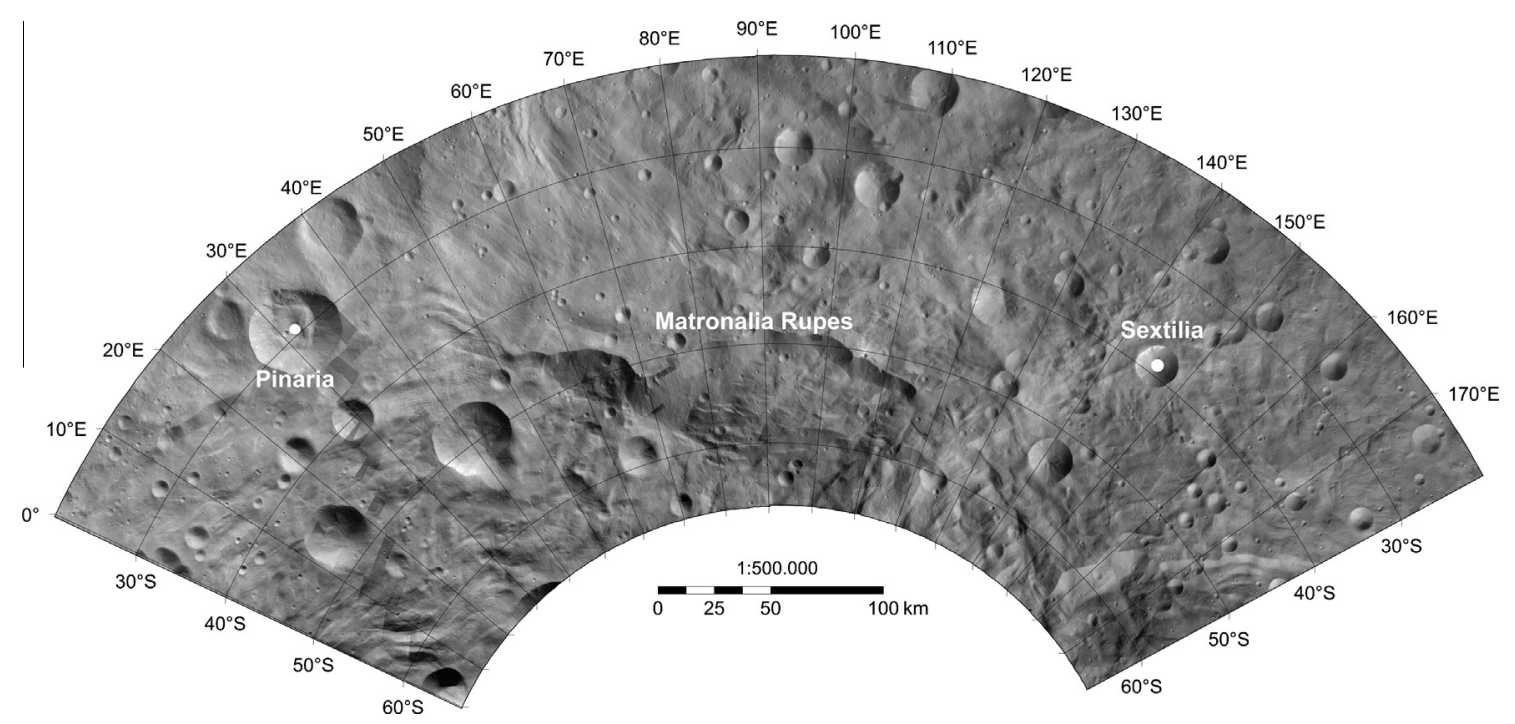

Fig. 2. FC LAMO mosaic of Av- 11 and Av-12, the boundary is located at $90^{\circ} \mathrm{E}$.

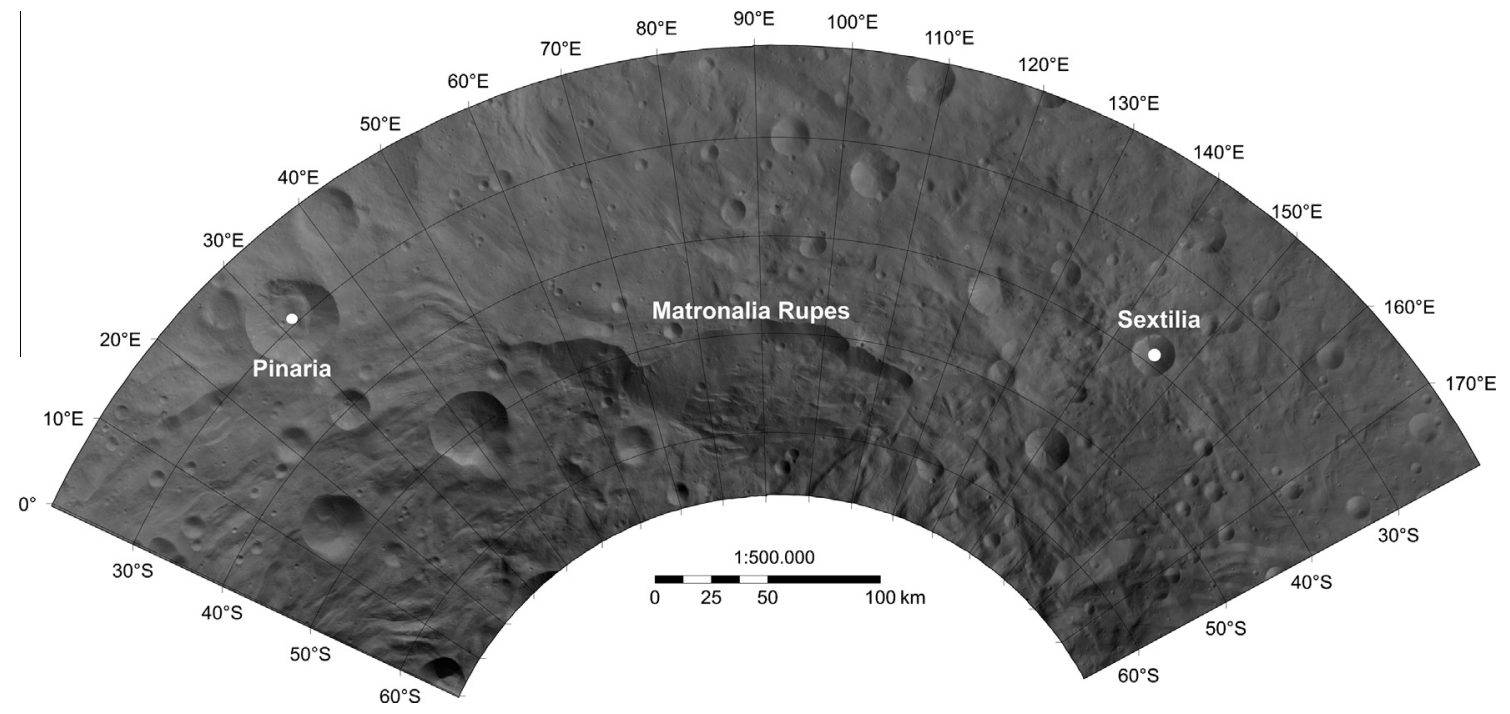

Fig. 3. FC HAMO mosaic of Av-11 and Av-12.

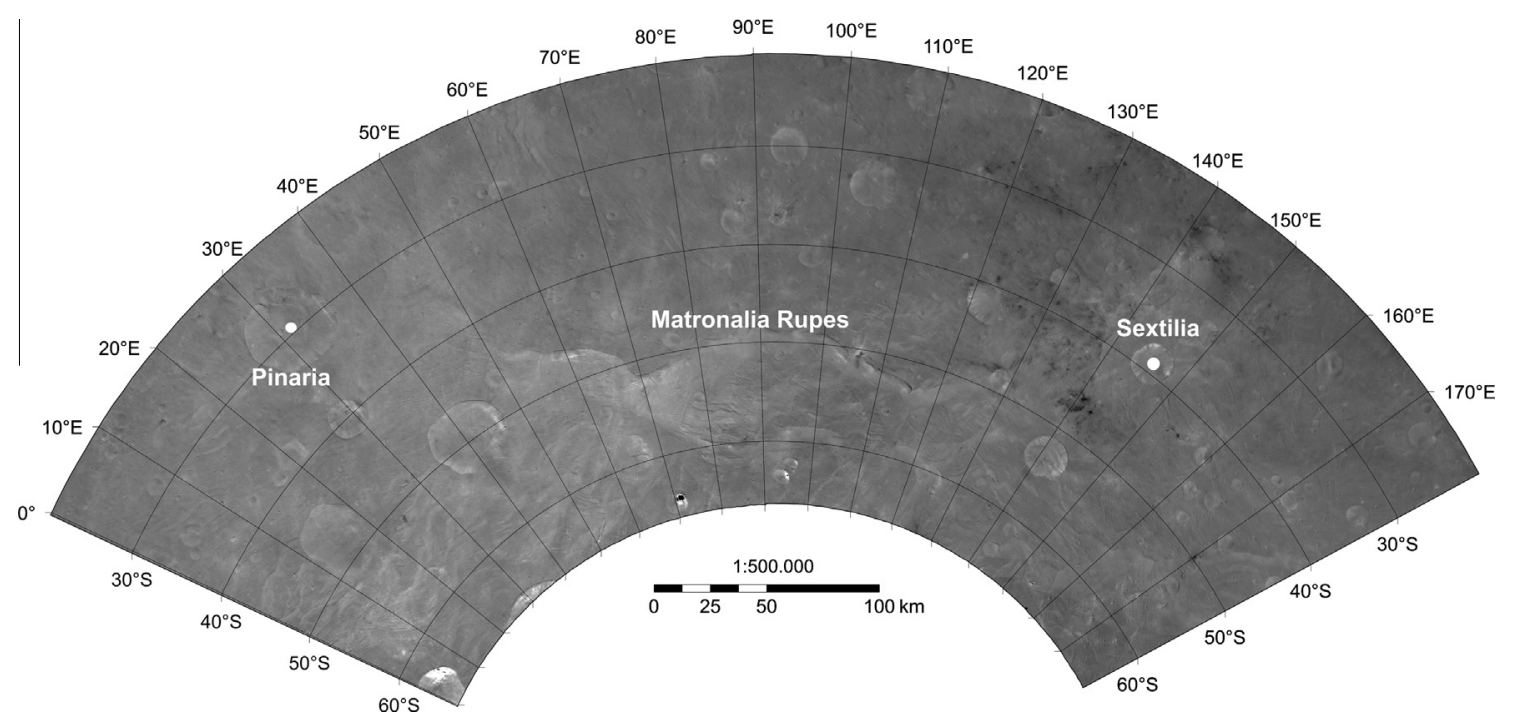

Fig. 4. Photometrically corrected HAMO FC mosaic of Quadrangle Av-11 and Av-12. 


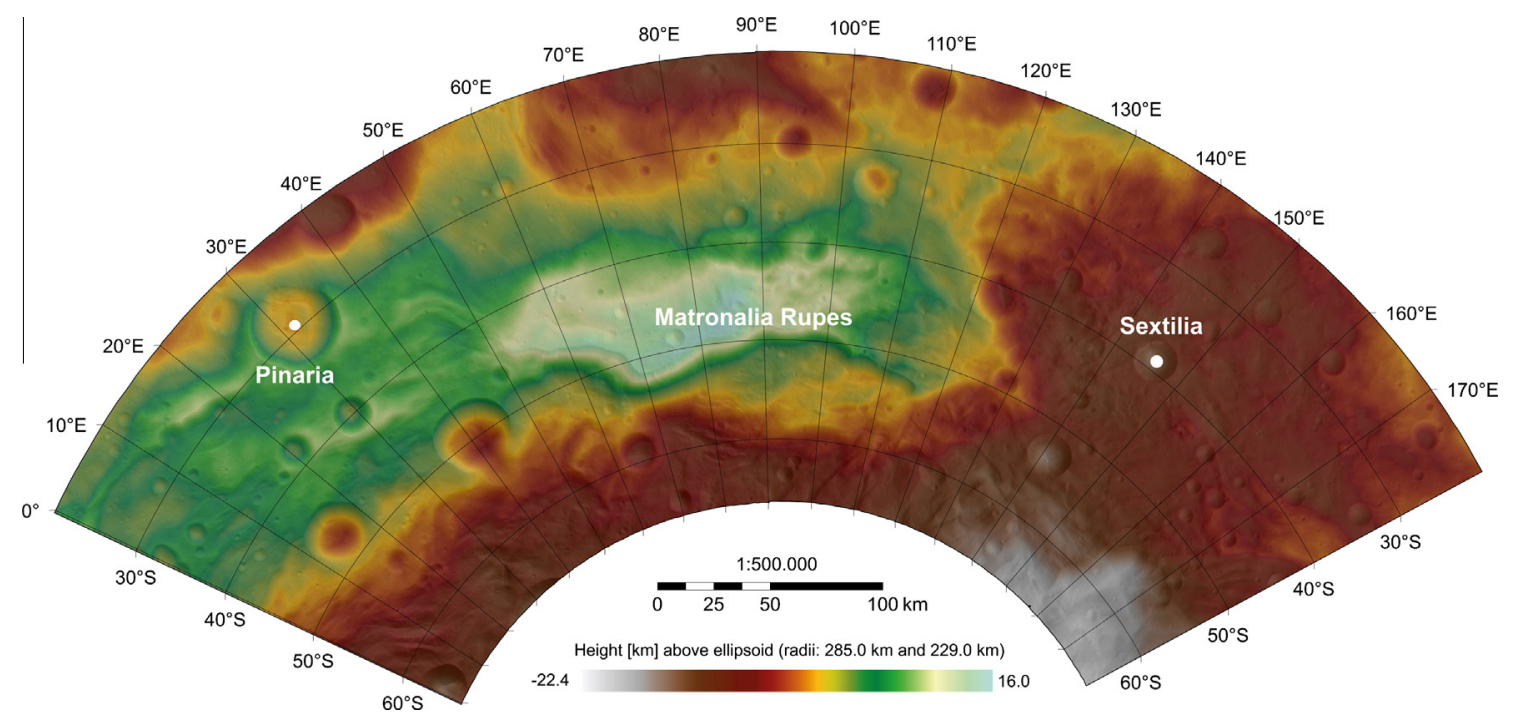

Fig. 5. HAMO-based digital terrain model (DTM) of Av-11 and Av-12.

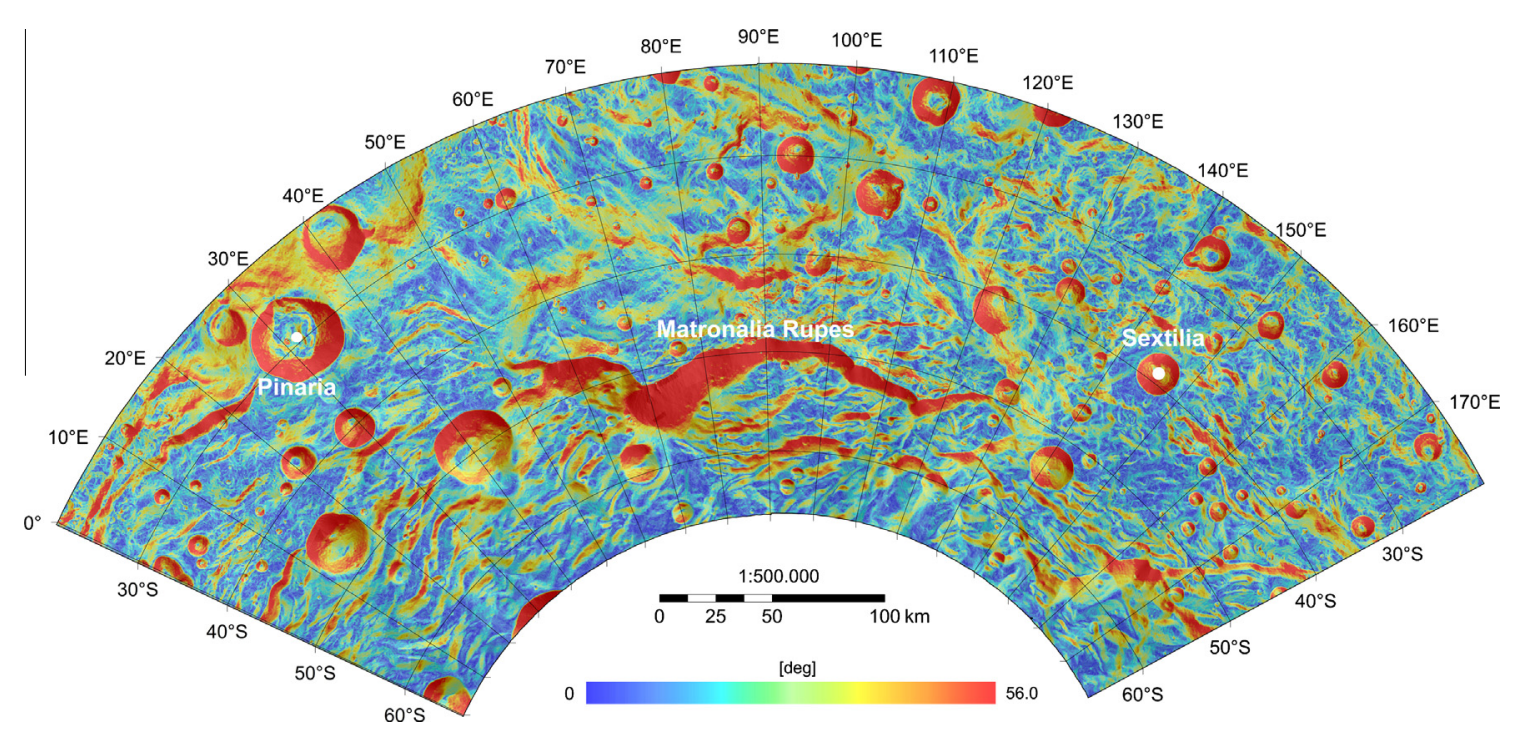

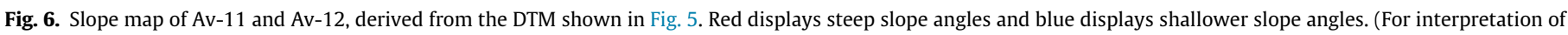
the references to color in this figure legend, the reader is referred to the web version of this article.)

The extreme topographic variations in this area allow craters to form on slopes (Jaumann et al., 2012). Numerous impact craters in the region are characterized by an unusual distribution of ejecta and/or shape of the crater rim, indicating anomalous conditions during the impact process (Jaumann et al., 2012; Krohn et al., 2012b; Schenk et al., 2012). A typical example of a bimodal crater is Helena (lat. $41.4^{\circ} \mathrm{S}$, long. $122.5^{\circ} \mathrm{E}$ ), which is asymmetric in shape and has a sharp rim on the uphill side and a smooth rim on the downhill side (Fig. 8) (Krohn et al., 2012b). The Southern part of both quadrangles is altered by the $500-\mathrm{km}$ diameter large Rheasilvia impact (centered at lat. $75^{\circ} \mathrm{S}$ and long. $301^{\circ} \mathrm{E}$ ) (Jaumann et al., 2012; Krohn et al., 2012a; Schenk et al., 2012) and also by the steep basin rim defined by Matronalia Rupes (see Figs. 14 and 16). The Rheasilvia Formation exhibits a variety of distinct units in Av-11 and Av-12, which were mapped as: (1) scarp wall material, (2) slump deposits, and (3) Rheasilvia ridge-and-groove terrain (Krohn et al., 2012a) (Figs. 9-11, respectively). The Rheasilvia structure partly overlaps an older large impact basin named Veneneia, which is centered at lat. $52^{\circ} \mathrm{S}$ and long. $170^{\circ} \mathrm{E}$ (Jaumann et al., 2012). The
Rheasilvia impact is deeper, with a topographic variation of $\sim 19 \mathrm{~km}$, whereas the Veneneia impact exhibits a lesser topographic variation of $\sim-12 \mathrm{~km}$. Veneneia is recognizable on the global topography map but is not obvious on the global mosaic because of the disruption and obscuration caused by Rheasilvia (Schenk et al., 2012).

\subsection{Description of map units (DOMU) of $A v-11$ and $A v-12$}

Fig. 9 shows type examples of the units defined in Av-11 and Av-12. The geological map of Av-11 is shown in Fig. 10 and that of Av-12 is shown in Fig. 11. The legend of both maps is displayed in Fig. 12.

ul - undifferentiated lobate material: This unit is characterized in the Sextilia and Fonteia crater by mass wasting material on the crater walls, floors and scarps. The unit exhibits lobate tongues or fan-shapes and a smooth to hummocky surface on the crater walls (Jaumann et al., 2012; Yingst et al., 2014). The unit also appears as 


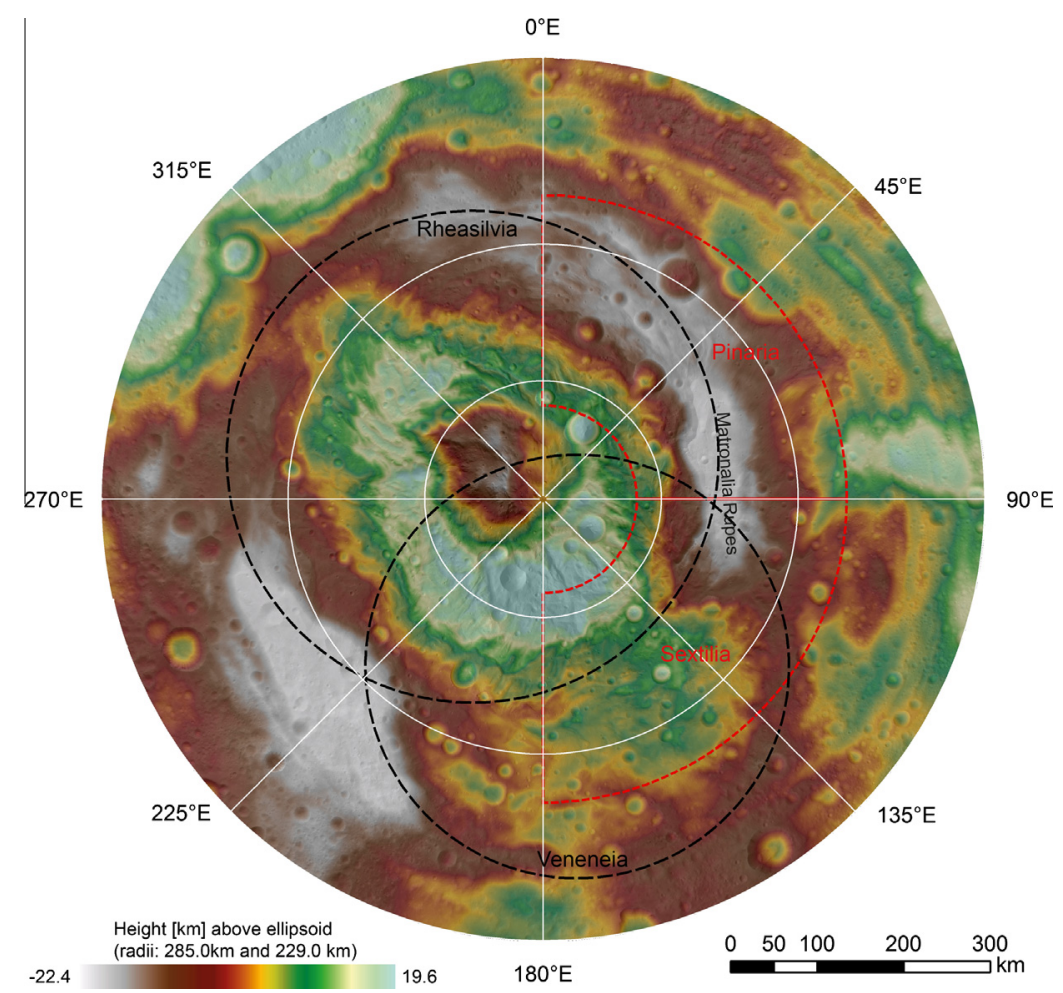

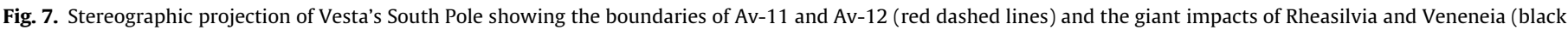
dashed lines). (For interpretation of the references to color in this figure legend, the reader is referred to the web version of this article.)

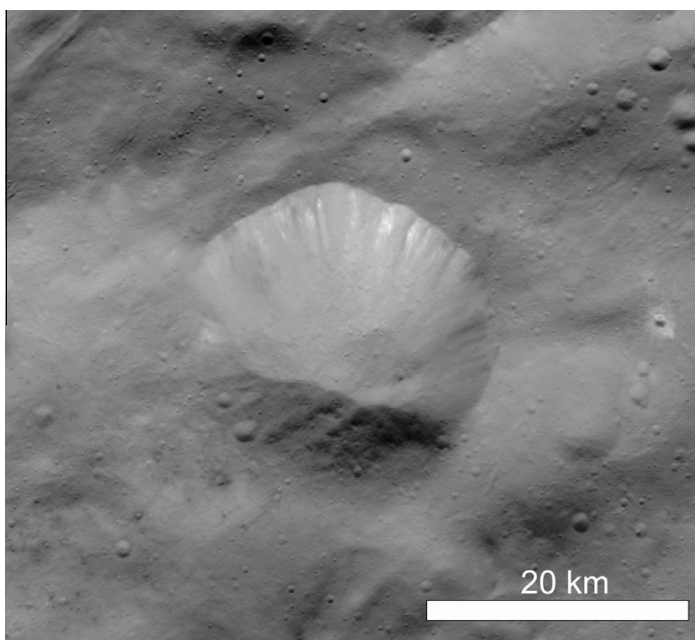

Fig. 8. Bimodal crater Helena (lat. $41.4^{\circ} \mathrm{S}$, long. $122.5^{\circ} \mathrm{E}$ ). The crater is $22 \mathrm{~km}$ in diameter and shows an asymmetric shape with a sharp rim uphill and a smooth rim downhill.

spur-and-gully morphologies on the crater and scarp walls. Type area: lat. $39^{\circ} \mathrm{S}$, long. $146^{\circ} \mathrm{E}$. RGB color: $85-255-0$.

Interpretation: These features are interpreted as debris fall, slump or slide through slope failure associated with a number of possible processes, including "seismic" shaking associated with impact crater formation or slope failure due to overburden (Williams et al., 2013; Yingst et al., 2014).

s - smooth material: Smooth material occurs in the NW part with a small branch to the central part. The surface is very smooth and relatively featureless at the LAMO resolution, with only small impact craters and minor linear features superimposed on the surface (Yingst et al., 2014). The unit is located on the topograph- ically higher region in Av-12. Type area: lat. $29^{\circ} \mathrm{S}$, long. $109^{\circ} \mathrm{E} . \mathrm{RGB}$ color: 20-255-115.

Interpretation: This unit likely consists of impact melt or finegrained materials deposited by mass movement (Yingst et al., 2014).

bcr - bright crater ray material: These deposits occur as bright streaks or radial halos around fresh impact craters, e.g., Myia crater, and covers the surrounding terrain. The unit exhibits a high albedo compared to the surrounding terrain in the FC images and the photometric corrected images as well as a bright white-toyellow color in the VIR Clementine-type ratio images (Yingst et al., 2014). Type area: lat. $50.5^{\circ} \mathrm{S}$, long. $106.2^{\circ} \mathrm{E}$. RGB color: $255-255-190$.

Interpretation: This unit is interpreted as high albedo impact ejecta consisting of materials excavated from Vesta; analogous to lunar crater rays (Yingst et al., 2014).

crm - complex crater ray material: These deposits occur as dark streaks, interrupted by bright material around the impact craters, and cover the surrounding terrain. The unit exhibits a mixture of low and high albedo compared to the surrounding terrain in FC images and photometric corrected images. Type area: lat. $37^{\circ} \mathrm{S}$, long. $92^{\circ}$ E. RGB color: 255-235-190.

Interpretation: This material likely consist of mixed ejecta of bright and dark materials excavated from Vesta.

dcr - dark crater ray material: These deposits occur as dark streaks, radial halos, or patches around the impact craters. The material covers the underlying material and extends to (or beyond) one crater diameter. The distribution of these deposits around a crater is often asymmetrical. The deposits exhibit low albedo in monochrome FC images and photometric corrected images as well as a dark purple color in the VIR Clementine-type ratio images. Type area: lat. $46.5^{\circ} \mathrm{S}$, long. $143^{\circ} \mathrm{E}$. RGB color: $255-255-0$.

Interpretation: Low albedo impact ejecta consisting of materials excavated from Vesta; alternatively, the rays consist of low albedo 

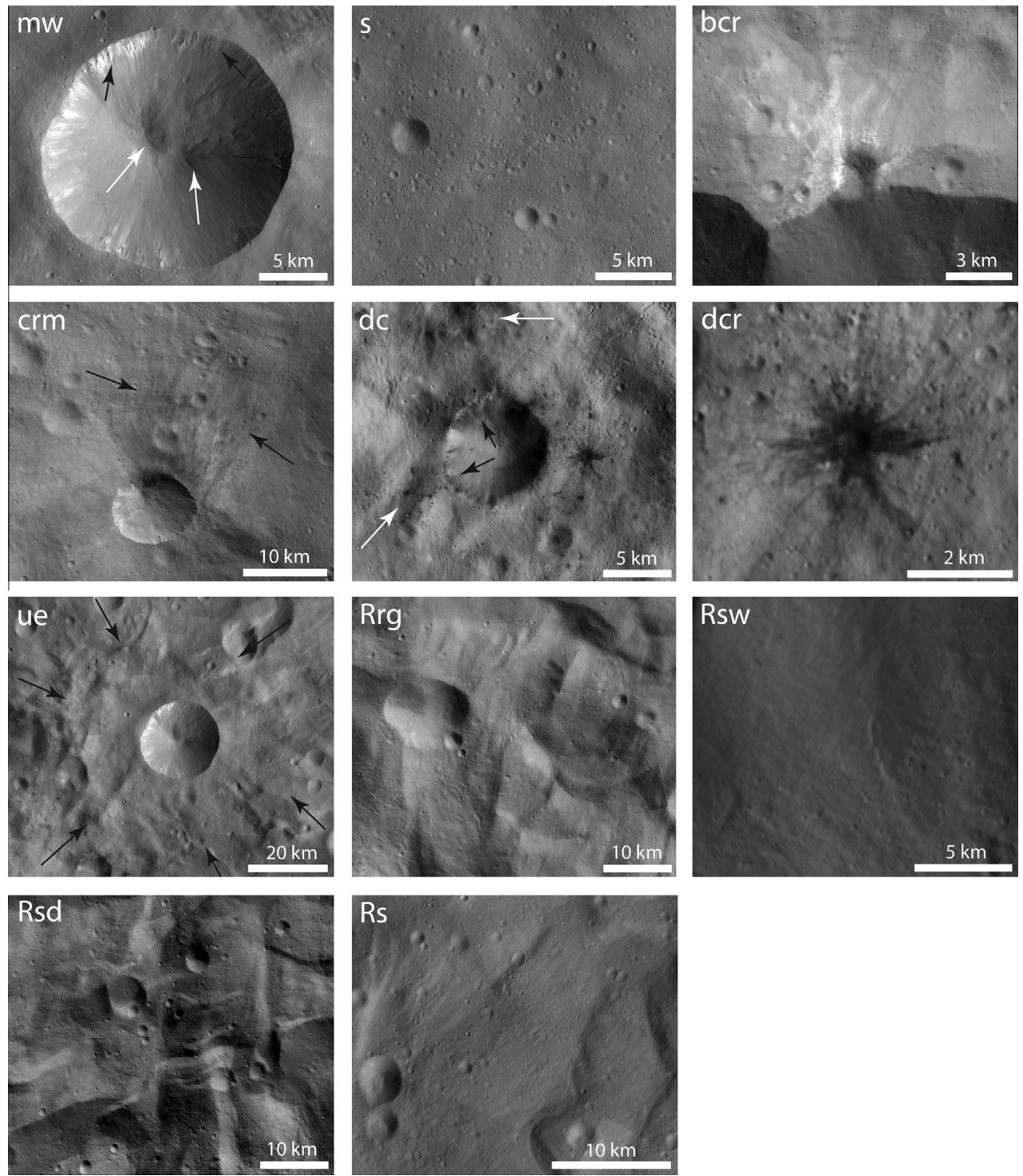

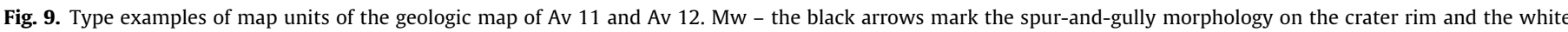

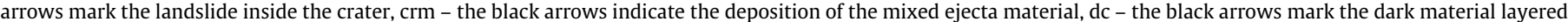
in the crater wall and the white arrows refer to dark ejecta spots from small impacts, ue - the black arrows mark the border of the ejecta material.

material dispersed from a dark, possibly carbonaceous impactor (Yingst et al., 2014).

dc-dark ejecta material: This unit is characterized in the Laelia crater by pronounced continuous crater rims elevated relative to the surrounding materials, and by a continuous, very low albedo ejecta blanket. Most parent craters exhibit a dark layer exposed in their interior wall (Yingst et al., 2014). The ejecta are widespread and mostly asymmetrically distributed with no obvious boundary but contain localized darker patches and spots of dark material. Type area: lat. $46.8^{\circ} \mathrm{S}$, long. $140.5^{\circ} \mathrm{E}$. RGB color: $255-170-0$.

Interpretation: The material consists of relatively fresh and unmodified crater deposits of very low-albedo - including rim, ejecta and some floor materials - emplaced by impact processes. The low albedo nature of the deposit may be due to the incorporation of dark material excavated from a dark underlying layer. The material may be associated with a dark layer within the crater wall (Yingst et al., 2014).

ue - undifferentiated ejecta material: This material is characterized by pronounced continuous crater rims elevated relative to the surrounding materials and by a continuous, relatively smooth ejecta blanket. Some deposits exhibit higher albedo (in FC monochrome) or a different color (in VIR) than that of the underlying terrain (Yingst et al., 2014). Type area: lat. $40^{\circ} \mathrm{S}$, long. 141E. RGB color: $230-230-0$.

Interpretation: The unit consists of relatively fresh and unmodified/well-preserved crater deposits - including rim, ejecta and some floor materials - emplaced by impact processes (Yingst et al., 2014).

Rrg - Rheasilvia ridge-and-groove-terrain: The unit consists of curvilinear ridges and grooves (see Fig. 2) at the kilometer to tens-of-kilometer length scales, which are predominantly sub-radially orientated with respect to the Rheasilvia basin (Yingst et al., 2014). The ridges are up to 2.5-km high (Otto et al., submitted for publication) and extend over the entire southern part of the quadrangle, ranging from $25 \mathrm{~km}$ up to $105 \mathrm{~km}$ into the quadrangle. Type area: lat. $61^{\circ} \mathrm{S}$, long. $128^{\circ} \mathrm{E}$. RGB color: 0-112-255.

Interpretation: Impact materials that form the floor of the Rheasilvia basin and are derived from the Rheasilvia impact event. Coriolis forces may have caused the spiral pattern of the ridges and 


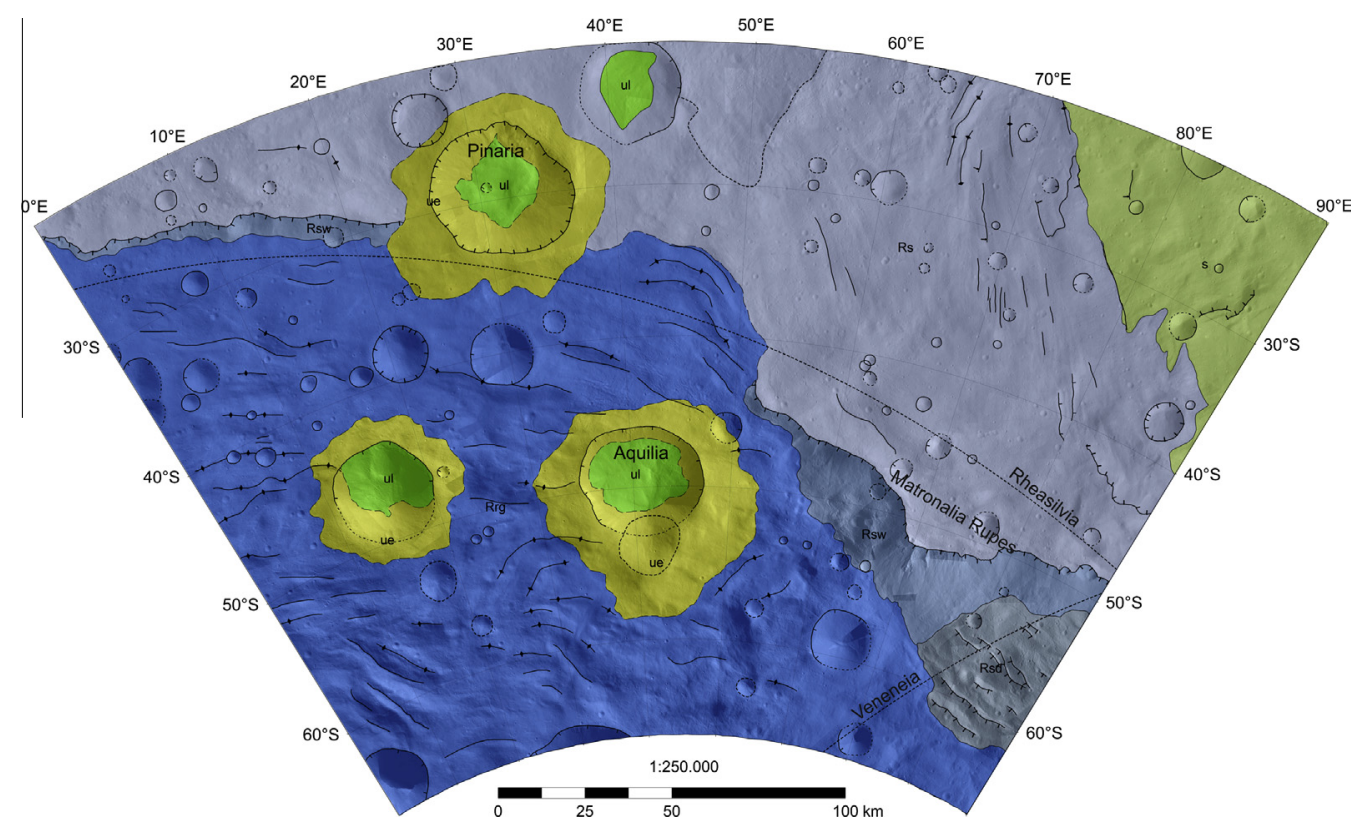

Fig. 10. Geologic map of Av-11 Pinaria.

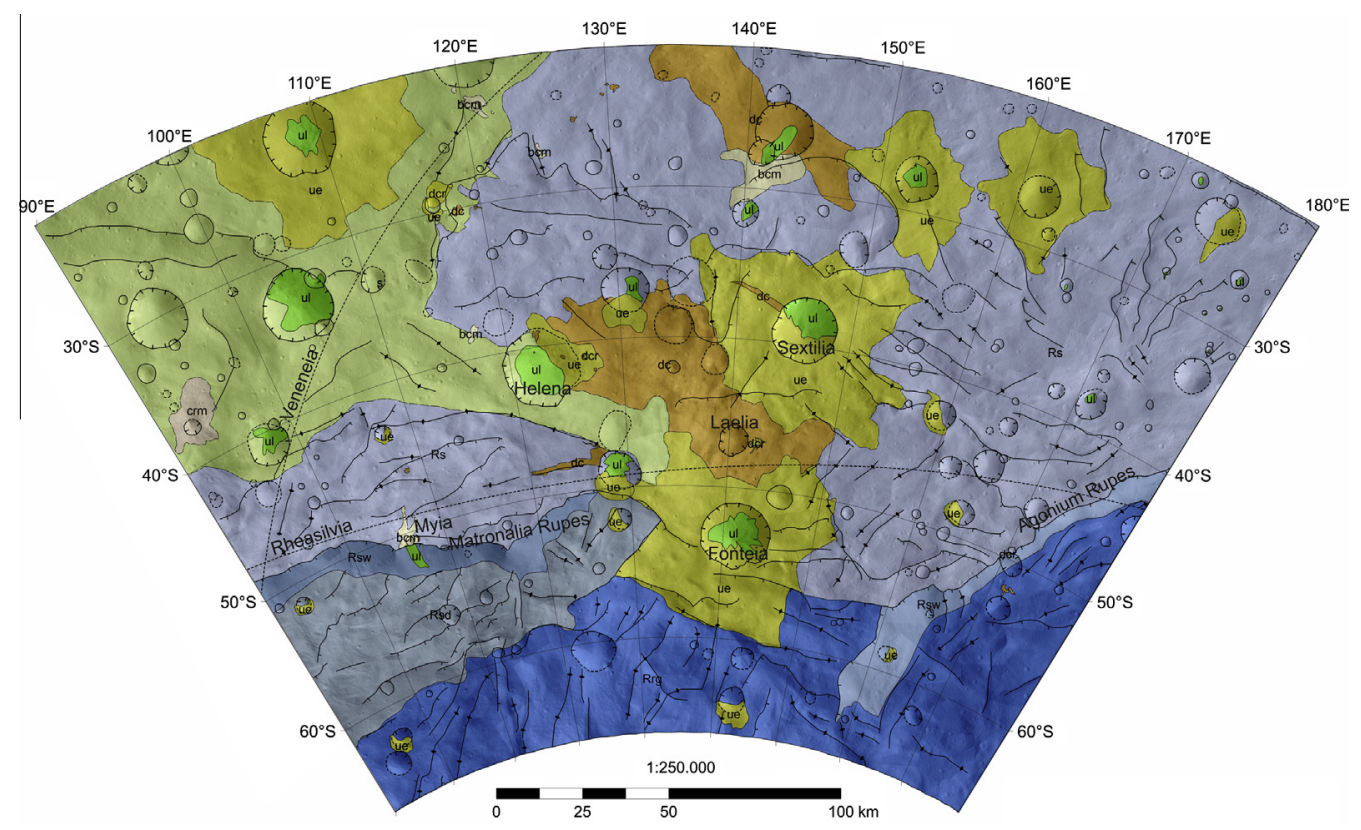

Fig. 11. Geologic map of Av-12 Sextilia.

grooves in the Rheasilvia basin (Otto et al., submitted for publication).

Rsw - Rheasilvia scarp wall material: The deposits exhibit a fresh morphology with a low crater density and a smooth and relatively featureless surface. Type area: lat. $52^{\circ} \mathrm{S}$, long. $108^{\circ} \mathrm{E}$. RGB color: 122-182-245.

Interpretation: The unit consists of relatively fresh material produced by mass wasting effects.

Rsd - Rheasilvia slump deposit: These deposits have a low crater density. The fine-grained material accumulates in lobate deposits of up to $9 \mathrm{~km}$ in length and $3 \mathrm{~km}$ in width. The morphology is formed by irregular blocks, which extends $\sim 80 \mathrm{~km}$ in width and approximately $5-30 \mathrm{~km}$ in length in Av-12. The blocks form terraces and exhibit a shallower slope than the scarp wall. Type area: lat. $55^{\circ}$ S, long. $103^{\circ} \mathrm{E}$. RGB color: $158-187-215$.
Interpretation: This unit consists of a rotational rock slump associated with slope instability and gravitationally triggered events (such as seismic shaking produced by impacts or internal quakes).

Rs - Rheasilvia smooth terrain: Rheasilvia ejecta material is widespread outside the crater rim, both covering the northeastern part of the Av-12 and defining the outer boundary of the Rheasilvia basin. The Rheasilvia smooth terrain has an irregular but smooth surface that is formed by scarps (up to $700 \mathrm{~m}$ in height with an average length of $35 \mathrm{~km}$ ), ridges and grooves (up to tens of kilometers lengths and up to $300 \mathrm{~m}$ in height). The terrain is topographically lower than the adjacent smooth terrain. Type area: lat. $31^{\circ} \mathrm{S}$, long. $165^{\circ}$ E. RGB color: $190-210-255$.

Interpretation: This unit likely consists of ejecta emplaced during the Rheasilvia impact event (Yingst et al., 2014). 


\section{LEGEND}

\section{Linear Features}

- scarp crest

$\longrightarrow$ ridge crest

- groove

_l_ flowlike features

\section{Geologic Contacts}

------ approximate

certain

\section{Craters and Depressions}

1... sharp crater rim

............. smooth crater rim

large crater

small crater

degraded crater

$\longrightarrow$ depression

\section{Geologic Units}

\section{Surficial Deposits}

ul undifferentiated lobate material

S smooth material

\section{Impact Crater Materials}

bcr bright crater ray material

$\mathrm{crm}$ complex crater ray material

dcr dark crater ray material

dc dark ejecta material

ue undifferentiated ejecta material

\section{Rheasilvia Formation}

Rrg Rheasilvia ridge-and-groove terrain

Rsw Rheasilvia scarp-wall material

Rsd Rheasilvia slump deposit

Rs Rheasilvia smooth terrain

Fig. 12. Map legend for the geologic map of Av-11 Pinaria and Av-12 Sextilia shown in Figs. 10 and 11.
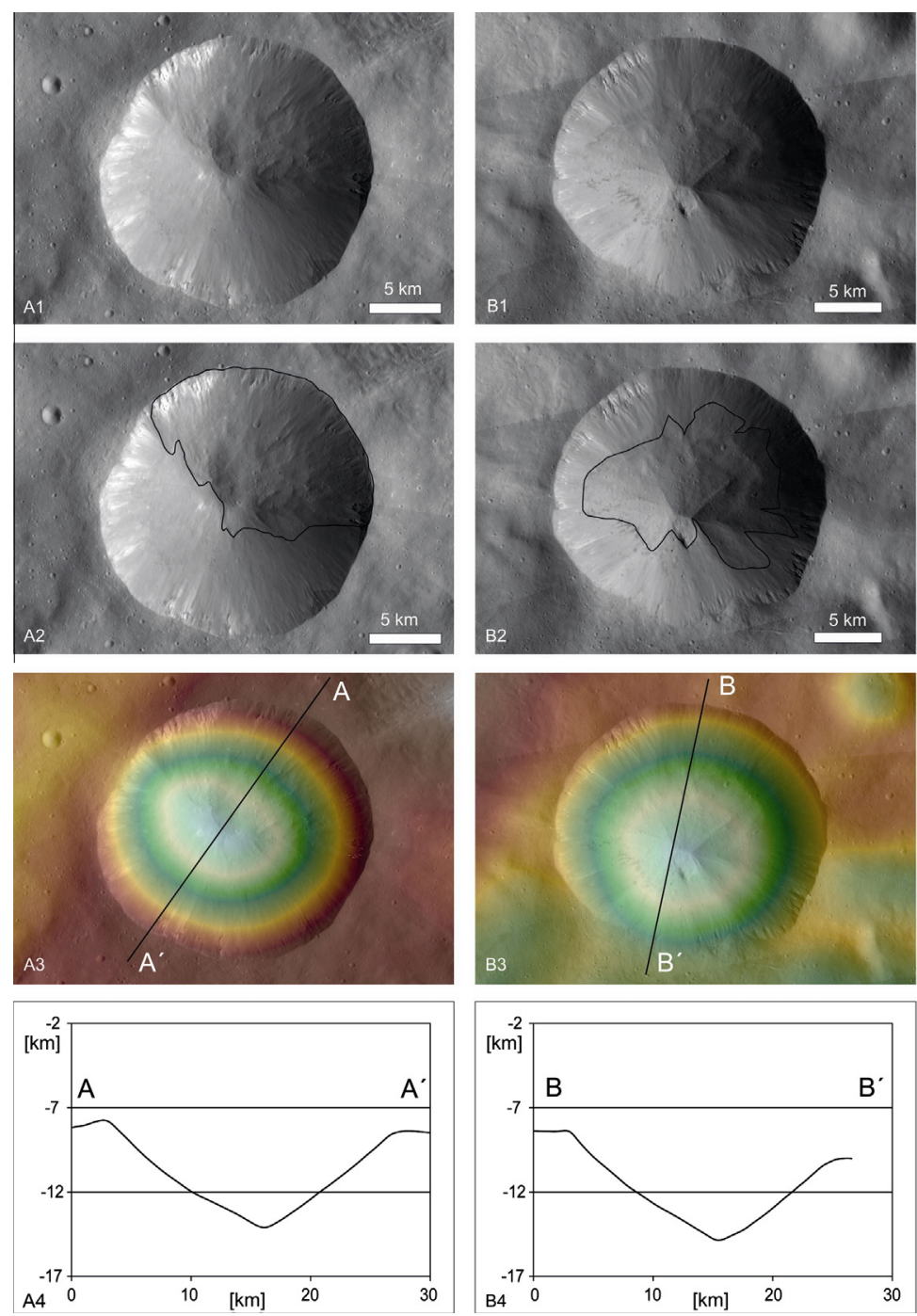
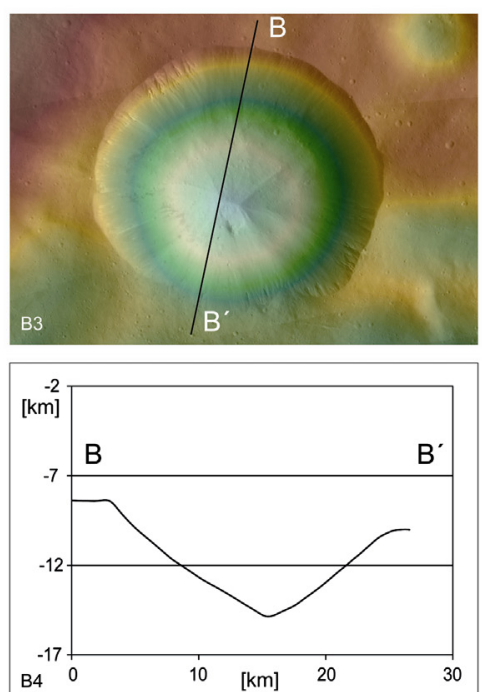
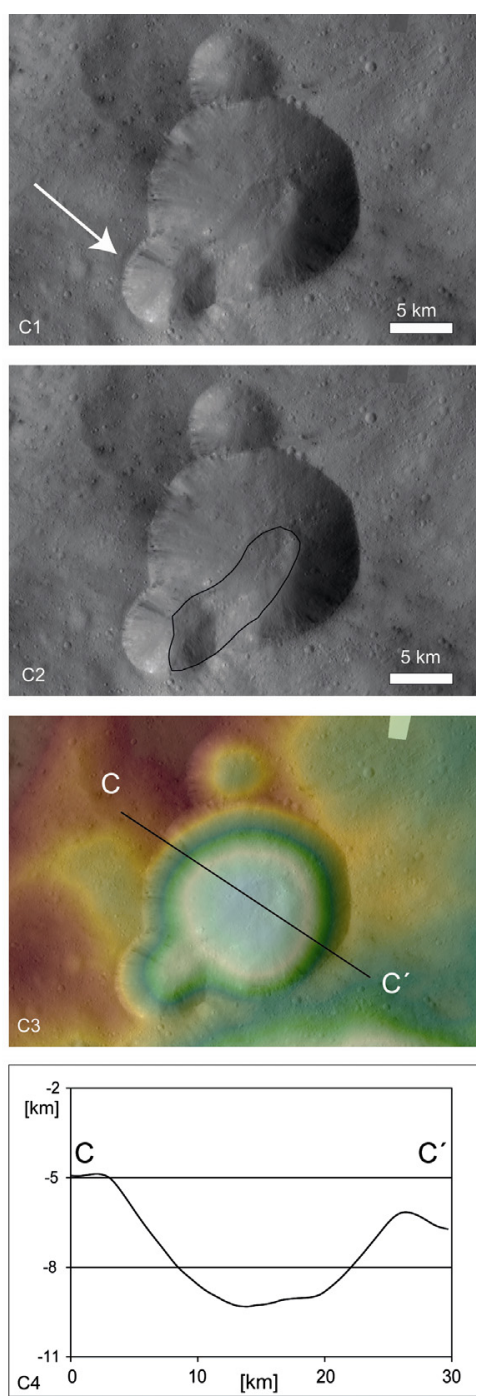

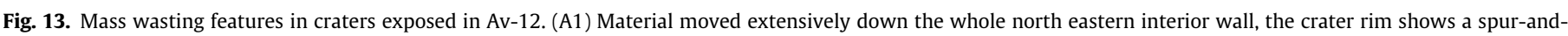

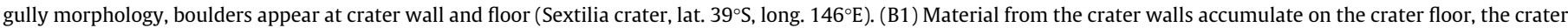

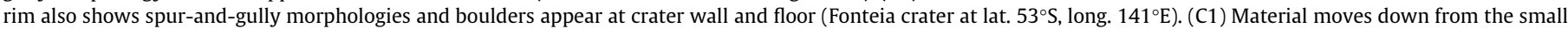

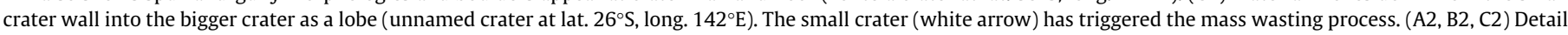
maps of mass wasting of the respective crater. (A3, B3, C3) Topographic maps of mass wasting of the respective crater. (A4, B4, C4) Profiles of the respective crater. 

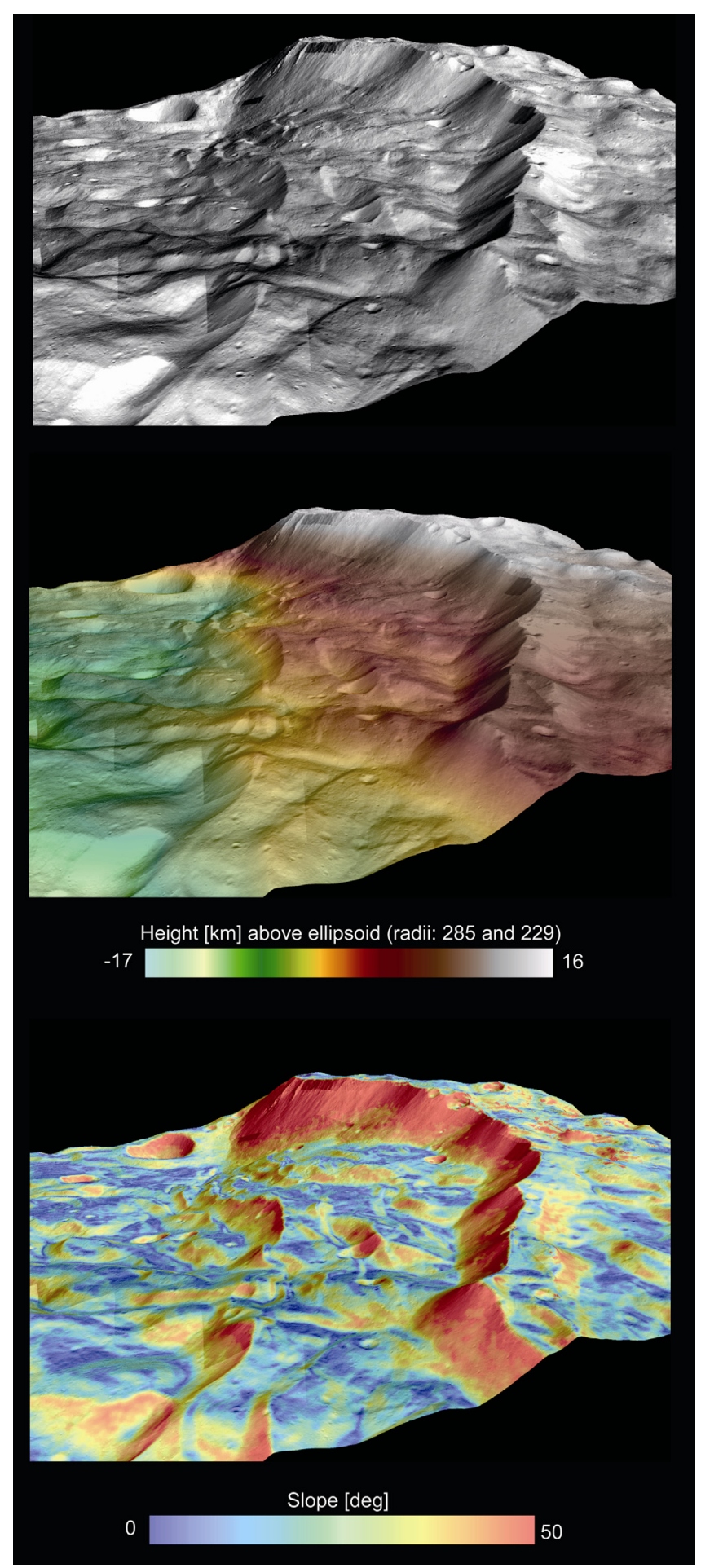

Fig. 14. Matronalia Rupes: Three-dimensional perspective view of Matronalia Rupes showing the stair-stepped pattern of displaced blocks (top); color-coded image-textured three-dimensional perspective view showing the height difference in elevation (middle); slope map showing the gradient of scarps and sliding blocks (bottom) (image width $=100 \mathrm{~km}$ ). (For interpretation of the references to color in this figure legend, the reader is referred to the web version of this article.)

\section{Characterization of mass wasting features in the Sextilia region}

The Sextilia region comprises different feature types that are largely due to mass wasting processes. Different types of dislocated material are found in the craters and at the large scarp of Matronalia

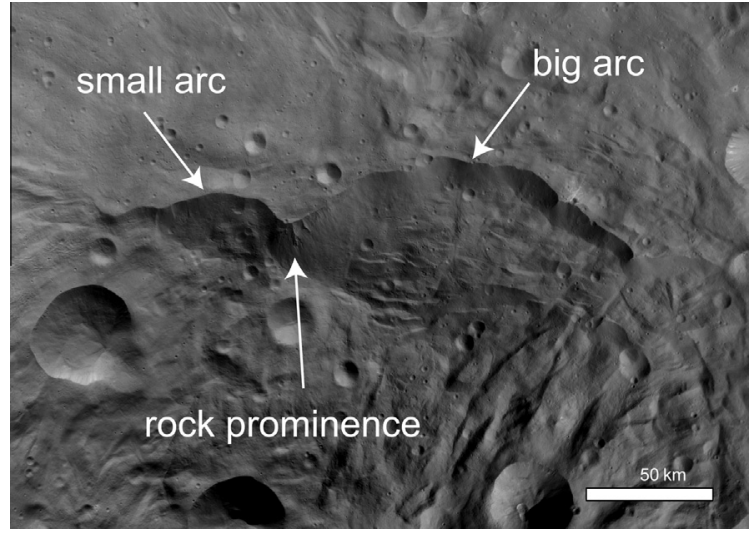

Fig. 15. The two arcs of Matronalia Rupes. They merge on their shared border resulting in a rock prominence ranging into the scarp.

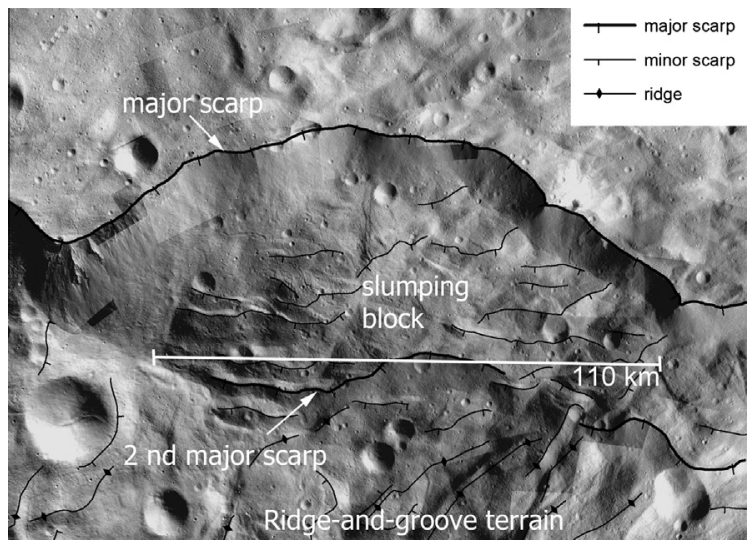

Fig. 16. Detailed map of Matronalia Rupes slumping block. Material slumped down the major scarp wall in a stair-stepped pattern, which is interrupted by minor scarps and covers the underlying Rheasilvia ridge-and-groove terrain in the South. The ridges and grooves are sub-radially orientated with respect to the slumping block (image width $=165 \mathrm{~km}$ ).

Rupes. In this section, the morphology of these features is described.

\subsection{Mass wasting in craters}

Some of the bowl-shaped craters in Av-11 and Av-12 larger than $6 \mathrm{~km}$ in diameter reveal features of mass wasting on the interior crater walls and on the floors. The profiles of the crater interiors exhibit a nearly parabolic form.

The Sextilia crater exhibits a smooth surface, which implies fine granular material composition. This material has extensively moved down the north eastern interior crater wall. Nearly half of the crater wall is covered by mass wasted material that form lobate tongues on the crater floor (A1, A2). The other half of the crater wall exhibits a fresh and smooth surface. The boulders on the crater wall and floor appear in addition to the spur-and-gully morphologies at the crater rim (Scully et al., 2013), which consist of alcoves, channels and deposition aprons. The channels of gullies are relatively straight, linear depressions that are parallel to one another. The channels are often bounded by levees of mass wasted material (Scully et al., 2013). The gullies originate at the spurs of material near the crater rims, which are positive topography features and appear to consist of competent material (Scully et al., 2013). Scully et al. (2013) describe these features as "linear gullies." 


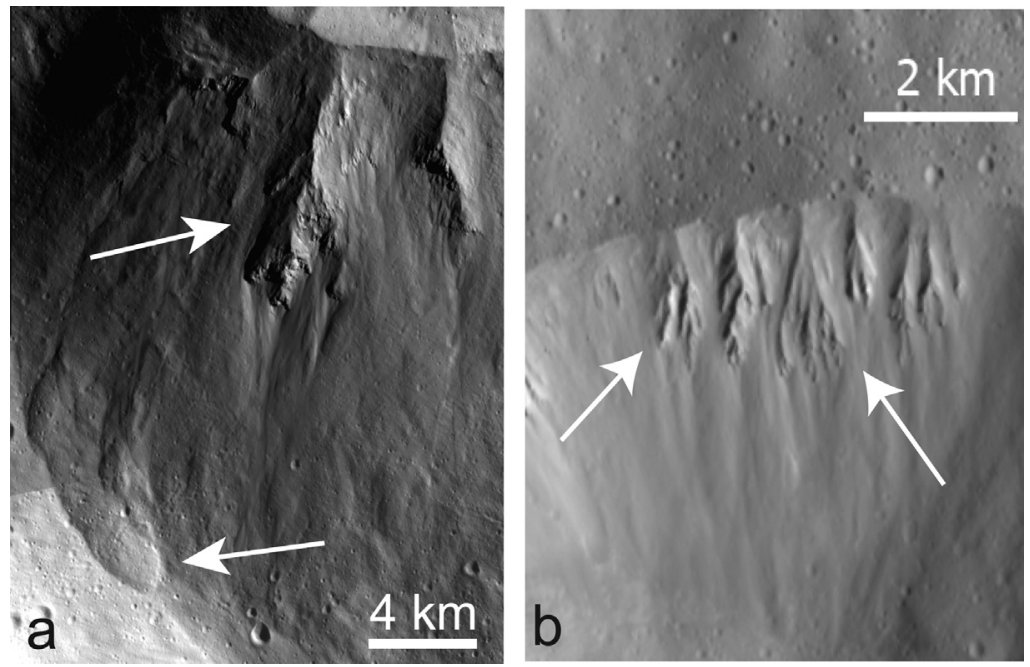

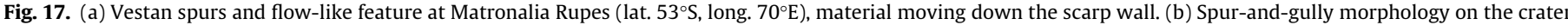
wall of Fonteia (lat. $53^{\circ} \mathrm{S}$, long. $141^{\circ} \mathrm{E}$ ).

In the case of the Fonteia crater (lat. $53^{\circ} \mathrm{S}$, long. $141^{\circ} \mathrm{E}$ ), the material originates from the crater walls (especially from the northeast) and accumulates on the crater floor as a result of the previous downslope movement (Fig. 13B1 and B2). The material covering the interior crater walls varies in thickness. The maximum thickness is found on the north eastern and southern crater walls. However, in general, the southern part is less covered by mass wasting material. The crater rim exhibits gullies incising into the crater wall. Boulders on the crater wall and on the floor are also visible.

Another form of mass wasting is observed at a $\sim 17 \mathrm{~km}$ in diameter crater in the northeastern part of Av- 12 (lat. $26^{\circ} \mathrm{S}$, long. $142^{\circ} \mathrm{E}$ ). A smaller impact crater with $\sim 7 \mathrm{~km}$ in diameter at the southwestern rim cuts the rim of the larger crater. A landslide was triggered by this impact (see arrow in Fig. 13C1), which overflowed over the small crater rim and was deposited northeastward down the wall of the larger crater in the form of a small lobate tongue (Fig. 13C1 and C2). Boulders and spur-and-gully morphologies are not observed at this location.

\subsection{Mass wasting at Matronalia Rupes}

The scarp Matronalia Rupes is located in the Southern hemisphere (centered at lat. $\sim 49.5{ }^{\circ} \mathrm{S}$ and long. $82.7^{\circ} \mathrm{E}$ ). Matronalia Rupes spans both Av-11 and Av-12 with an approximate length of $208 \mathrm{~km}$. The scarp height varies from $\sim 22 \mathrm{~km}$ in the middle to $\sim 5 \mathrm{~km}$ on the East side. It is a steep scarp with a slope of $>40^{\circ}$ at the top and $26-31^{\circ}$ at the bottom (Fig. 14). The scarp exhibits a slightly spoon-like shape in cross section. The scarp consists of a small arc on the West side and a large arc on the East side. The two arcs merge on their shared border resulting in a rock prominence ranging into the scarp (Fig. 15). Matronalia Rupes separates the Rheasilvia smooth terrain from the Rheasilvia ridge-andgroove terrain in Av-11 and Av-12.

The large arc on the East side of Matronalia Rupes exhibits a collapse process. A huge slump block of up to $110 \mathrm{~km}$ in length appears to have slipped down the scarp wall and formed a wavy morphology with a low crater density. Thin elongated blocks between $5 \mathrm{~km}$ and $30 \mathrm{~km}$ in length and oriented parallel to the scarp are exposed. These blocks appear to have been continuously slipping down. The upper surface of the blocks rotated backwards and formed depressions. The profiles of the blocks indicate a
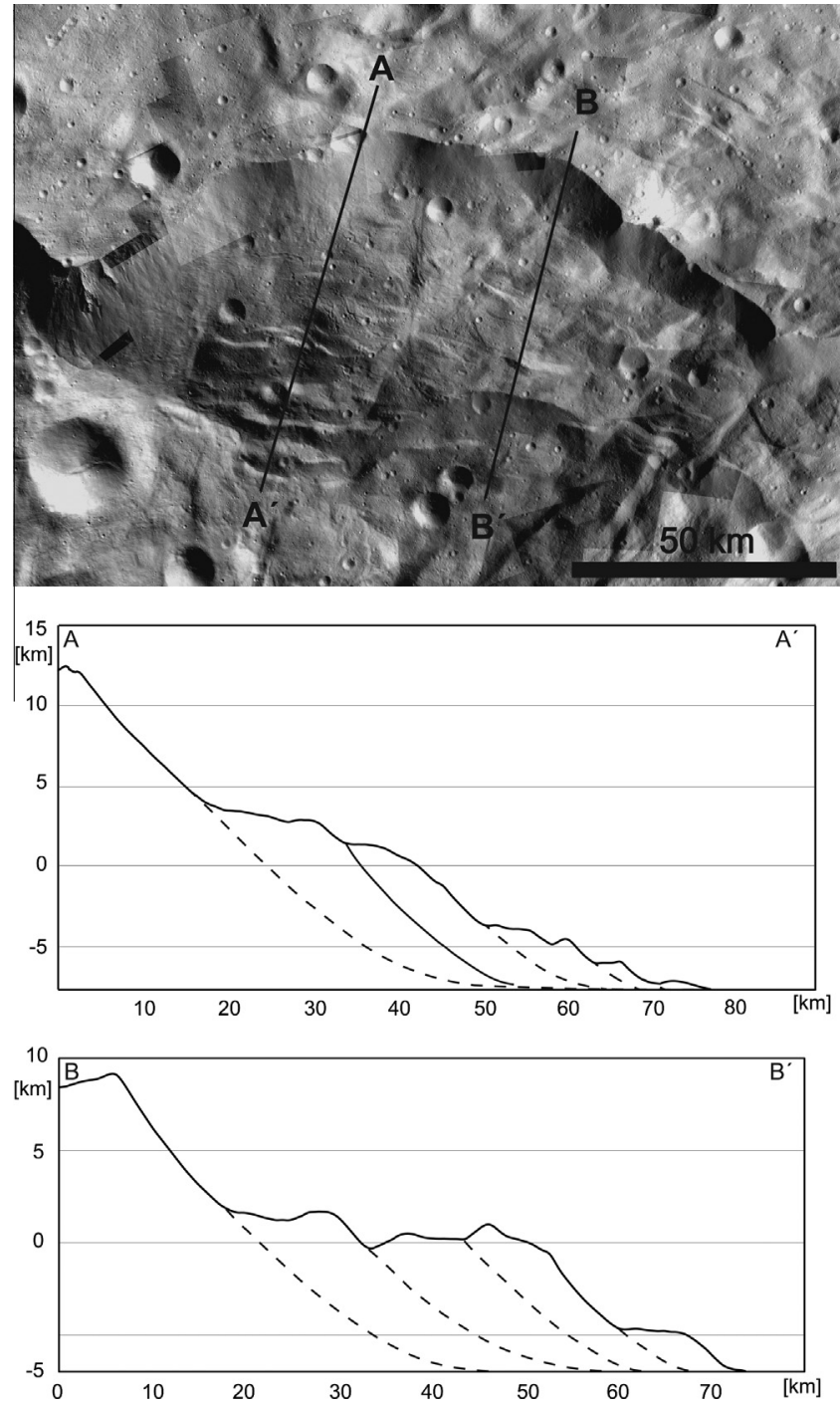

Fig. 18. Profile of Matronalia Rupes slumping block as shown in Figs. 14 and 16. 
stepped pattern, which implies displaced blocks of material (Figs. 14 and 18). The blocks are bordered by the Rheasilvia ridge-and-groove terrain (in the South and East) and by the rock prominence in the West.

This huge slumping block exhibits a second steep scarp with a slope between $\sim 26^{\circ}$ and $40^{\circ}$. This scarp separates these blocks from the south polar ridged-and-groove terrain (Fig. 16). Different overlapping processes can be identified. The slump block described above covers the underlying Rheasilvia ridge-and-groove terrain.

However, the scarp wall exhibits a fresh, smooth and relatively featureless surface with a very low crater density. At the top of the scarp wall, a spur-and-gully morphology is observed. The alcoves of this morphology extend up to $9 \mathrm{~km}$ in length and $3 \mathrm{~km}$ in width and are encircled by fine-grained material. At the rock prominence, a flow-like mass wasting feature occur. Fine-grained material wasted down the scarp wall and accumulated in a lobate deposit, approximately $7 \mathrm{~km}$ from the base of the wall.

\section{Discussion}

\subsection{Landslides and spur-and-gully morphology}

The crater rim structures on the craters found in Av-11 and Av-12 exhibit some similarities to martian gullies. Malin and Edgett (2000) noted that martian landforms resemble terrestrial gullies that are formed by a combination of processes, including overland flow, head-ward sapping, debris flow, and other mass movements - all processes that, on Earth, involve the action of water. Malin and Edgett (2000) and Lucchitta et al. (1992) proposed that these gullies formed by underground water moving within and along bedrock layers. On Mars, gullies occur on steep slopes, especially on the walls of craters (Malin and Edgett, 2000; Treiman, 2003). Gullies are found more often on pole-ward facing slopes than on equator-ward facing slopes and occur in the mid- and high-latitudes of Mars. Over $90 \%$ of the gullies occur south of the equator (Malin and Edgett, 2000; Treiman, 2003). Furthermore, the spur-and-gully morphology at Matronalia Rupes exhibit similarities to those found on Mars by Treiman (2003) and Lucchitta et al. (1992) at Nirgal Valles and Valles Marineris, respectively.

The typical morphologic characteristics are alcoves, channels and deposition aprons (Malin and Edgett, 2000; Treiman, 2003). This alcove-channel-apron morphology is the primary criterion for gully identification (Hartmann et al., 2003).

The alcove is a spoon-like depression at the head of the gully and begins at or below the top of the slope (see Malin and Edgett (2000) and the many reports in the pre-Mars Global Surveyor literature). Vestan landslides exhibit well-defined lengthened alcoves that are similar in morphology to martian alcoves. The Vestan channels, although degraded, are incised into the crater walls in a manner similar to the martian channels.

Despite the lower resolution of the Dawn images compared to the martian imaging data [1.5-12.0 m/pixel] from the Mars Global Surveyor Mars Orbiter Camera (Malin and Edgett, 2000), debris aprons are also visible. Therefore, those debris aprons exhibit all of the characteristics of martian gullies, although there is no evidence for water and there is no atmosphere on Vesta.

A dry formation of the martian gullies has been described in (Treiman, 2003), who proposed that gullies may form by avalanches of fine granular material without water. Additionally, Shinbrot et al. (2004) demonstrated that several features of liquid-erosional flows can be produced by dry granular material.

Using analog experiments with low-density and micro-scaled hollow ceramic beads, Shinbrot et al. (2004) successfully demonstrated the formation of structures with the alcovechannel-apron morphology. The formation of such flow-like features exposed at Matronalia Rupes (Fig. 17) is one example of such dry formation.

Bart (2007) reported a dry formation of the alcove-channelapron morphology on the Moon. Similar to Vesta, the Moon has no evidence for liquid water. The lunar spur-and-gully morphology is also similar to martian spur-and-gully morphology and has been observed on crater slopes in the northern hemisphere (Bart, 2007). The lunar surface is covered by the fine-grained loose material known as regolith. Due to the almost non-existent atmosphere of the Moon, impacts of all sizes (as well as the steady bombardment of the lunar surface by charged atomic particles from the Sun and stars), shattered the lunar surface into regolith (Heiken et al., 1991).

Vesta's surface was hit by numerous large and small projectiles, causing the formation of a regolith layer. Thus, we expect similar formation processes of the spur-and-gully morphology to those on the Moon.

\subsection{Scaling}

Despite the morphological resemblance of the martian and lunar gullies with those found on Vesta, the relatively low gravity and airless environment on Vesta deserves consideration. At atmospheric pressures below $1300 \mathrm{~Pa}$, the Stokes-like behavior of materials (the particle settling speed $v$ is proportional to the square of the particle diameter $d$, the gravitational acceleration $g$, and the density difference $\Delta \rho$ and is inversely proportional to the viscosity $\eta$, describing the fluid-like character of the granular particles, $v=\frac{\Delta \rho d^{2} g}{18 \eta}$ ) merge to ballistic movements of the grains (Shinbrot et al., 2004). Use of this threshold is inappropriate on both Vesta and the Moon due to the non-existent atmospheric pressure. Nevertheless, gullies are still easily identified.

Shinbrot et al. (2004) experimentally created spur-and-gullies were produced under dry but atmospheric pressure conditions. A lower gravity was simulated by low-mass glass beads to $1 / 15$ of the Earth's gravity conditions $\left(0.65 \mathrm{~m} / \mathrm{s}^{2}\right)$. As these experiments were set up to investigate gullies on Mars, the simulated gravity exceeds the Vestan gravity by a factor of 2.6. The gully length on Vesta exceeds the experimental scale by approximately 3 orders of magnitude. These differences between the laboratory experiments and the environment on Vesta, however, seem to have little effect on the features' morphology. As expected, the principal effect of gully formation is dependent on the properties of the material and the formation process. Thus, the appearances of the two cases are similar and exhibit the fluid-like movement of the material in both scales. This observation regarding the scaling of the geological features with laboratory experiments was also discussed in Shinbrot et al. (2004) and Walsh et al. (2003).

\subsection{Mass movement}

Mass wasting and downslope movement, such as granular flows, landslides and slump blocks, are common processes in the gravitational environment of planets, moons and asteroids (Miyamoto et al., 2007; Shingareva and Kuzmin, 2001; Singer et al., 2012). The stability of materials on a slope in a gravitational field is constrained by the material strength, elastic-plastic properties, material failure and internal friction. Depending on these factors, different types of mass movements occur. Material on a slope remains stable under the influence of gravity as long as the forces of friction and cohesion exceed the gravitational force. If this condition is violated, the slope material moves along a surface of raptures until the forces compensate again and a new state of stability is reached. Friction and cohesion can be alleviated by seismic shaking from impacts or internal quakes (Richardson et al., 2004, 
2005). The pressure wave of such an event affects the cohesion and friction and thus can weaken equilibrium conditions with gravity. Even if this event occurs only over a short period of time, it can trigger a slide to move downslope. The slide will continue moving until a new stable condition is reached, the kinetic energy is converted into heat, and particle deformation occurs. Various landslide types (e.g., translational or rotational slumps or granular slides), can be described by gravity-driven mass movements. Along the Matronalia Rupes scarp, rotational slump blocks are identified. A rotational slump is most commonly observed in homogeneous and compacted material and is a motion of compacted material on a curved surface of rapture (Cruden and Varnes, 1996). The displacement of the center of mass (from the center of the circle that is formed by the surface of rapture) causes a torque that, upon exceeding the friction and cohesion forces at the surface of rupture, drives the masses downward (De Blasio, 2011). After slump and reaching a stable position, the mass wasting feature exhibiting a scarp and head at the upper part and a foot and toe at the downhill part of the slide. Secondary slump blocks might originate from the main slump block during the motion or afterwards. These features are observed at Matronalia Rupes (see the profiles in Fig. 18).

Intra-crater material is generated by the impact process. After excavation of the transient crater, the intra-crater debris comes to a momentary stop and begins to move downwards towards the center. As a result, the over-steepened rim of the crater is accelerated downward due to gravity (Melosh, 1989). The effects of this collapse range from debris avalanches and boulders rolling down the crater wall to overall alteration of the crater form (Melosh, 1989). Approximately simultaneous avalanches can merge in the central crater region and build up piles of debris of significant dimension (Quaide et al., 1965). Generally, crater degradation caused by the effect of gravity on material from the rim and inner walls to the crater floor modifies the transient crater, but also occurs after the crater formation triggered by seismic shaking of subsequent impacts.

Our investigated craters in Av- 11 and Av- 12 exhibit slumped material features as well as boulders on the crater walls and floors. On Phobos, the inter-crater landslides also exhibit similarities to those on Vesta, e.g., smooth relatively steep crater walls and the landslide body inside the crater. The mass movement on Phobos is related to seismic shaking due to meteoroid impacts such as those we expect on Vesta.

\section{Conclusions}

The discovery of the mass-wasting features demonstrates that even a small planetary body such as Vesta can exhibit different types of mass wasting processes. A survey of the mass wasting features in craters confirmed that normally liquid-formed features such as spur-and-gully morphologies can be formed under dry conditions. The morphological similarity between the martian and Vestan gullies and the lack of water on Vesta indicate that dry landslides can create such morphologies without water. Steady bombardment of the Vestan surface by impacts and the influence of space weathering formed a fine-grained regolith on Vesta. However, the low gravity on Vesta reduces the particle settling speed and prolongs the fluidization of particle flows (Shinbrot et al., 2004). Thus, such spur-and-gully morphology as found on Vesta can be produced by dry granular material when individual particle settling is slower than the characteristic debris flow speeds (Shinbrot et al., 2004).

The (crater) research in this study also indicates a collapse process in the craters. Impact-produced over-steepened crater rims cause slope instability and gravity-forced material to move down the crater wall. Slope instability also occurs on Matronalia Rupes.
Matronalia Rupes exhibits all of the characteristic properties of rotational rock slumping affected by slope instability and gravitationally triggered events (such as seismic shaking produced by impacts or internal quakes, similar to the landslides on Lutetia).

\section{Appendix A. Supplementary data}

Supplementary data associated with this article can be found, in the online version, at http://dx.doi.org/10.1016/j.icarus.2014.03. 013.

\section{References}

Bart, G.D., 2007. Comparison of small lunar landslides and martian gullies. Icarus 187, 417-421.

Chuang, F.C. et al., 1998. Intracrater landslides on Callisto: Observations from the Galileo Nominal Mission. Lunar Planet. Sci. 29, 1331 (Abstracts).

Cruden, D.M., Varnes, D.J., 1996. Landslide types and processes. In: Turner, A.K. Schuster, R.L. (Eds.), Landslides: Investigation and Mitigation (Special Report). National Research Council, Transportation and Research Board Special Report Washington, DC, USA, pp. 36-75.

De Blasio, F.V., 2011. Introduction to the Physics of Landslides - Lecture Notes on the Dynamics of Mass Wasting. Springer.

De Sanctis, M.C. et al., 2011. The VIR spectrometer. Space Sci. Rev. 163, 329-369. Hansen, V.L., 2000. Geologic mapping of tectonic planets. Earth Planet. Sci. Lett. 176, 527-542.

Hartmann, W.K. et al., 2003. Martian hillside gullies and icelandic analogs. Icarus $162,259-277$.

Heiken, G.H. et al., 1991. Lunar Sourcebook - A User's Guide to the Moon.

Jaumann, R. et al., 2012. Vesta's shape and morphology. Science 336, 687-690.

Krohn, K. et al., 2012a. Geologic mapping of the Av-12 Sextlia quadrangle of Asteroid 4 Vesta. Lunar Planet. Sci. 43, 1901-1902 (Abstracts).

Krohn, K. et al., 2012b. Scarps and unusual crater in the Sextilia region on Vesta. LPI Contributions 1667, 6223

Lucchitta, B.K. et al., 1992. The canyon system on Mars. In: Kieffer, H.H. (Ed.), Mars, pp. 453-492.

Malin, M.C., Edgett, K.S., 2000. Evidence for recent groundwater seepage and surface runoff on Mars. Science 288, 2330-2335.

Massironi, M. et al., 2012. Geological map and stratigraphy of Asteroid 21 Lutetia. Planet. Space Sci. 66, 125-136.

Melosh, H.J., 1989. Impact cratering: A geologic process.

Miyamoto, H. et al., 2007. Regolith migration and sorting on asteroid Itokawa. Science 316, 1011-1014.

Moore, J.M. et al., 1999. Mass movement and landform degradation on the Icy Galilean satellites: Results of the Galileo Nominal Mission. Icarus 140, 294-312.

Nass, A. et al., 2011. Implementation of cartographic symbols for planetary mapping in geographic information systems. Planet. Space Sci. 59, 1255-1264.

Otto, K.A. et al., 2013. Mass-wasting features and processes in Vesta's south polar basin Rheasilvia. J. Geophys. Res. - Planets 118, 2279-2294.

Preusker, F. et al., 2012. Topography of Vesta from Dawn FC Stereo images. Lunar Planet. Sci. 43, 2012-2013 (Abstracts).

Quaide, W.L. et al., 1965. Gravitative effects on lunar impact structures. Ann. NY Acad. Sci. 123, 563-572.

Richardson, J.E. et al., 2004. Impact-Induced Seismic Activity on Asteroid 433 Eros: A Surface Modification Process. Science 306, 1526-1529.

Richardson, J.E. et al., 2005. The global effects of impact-induced seismic activity on fractured asteroid surface morphology. Icarus 179, 325-349.

Roatsch, T. et al., 2012. High resolution Vesta High Altitude Mapping Orbit (HAMO) Atlas derived from Dawn Framing Camera images. Planet. Space Sci. 73, 283 286.

Roatsch, T. et al., 2013. High-resolution Vesta Low Altitude Mapping Orbit Atlas derived from Dawn Framing Camera images. Planet. Space Sci. 85, 293-298.

Russell, C.T. et al., 2012. Dawn at Vesta: Testing the protoplanetary paradigm. Science 336, 684-686.

Schenk, P. et al., 2012. The geologically recent giant impact basins at Vesta's South Pole. Science 336, 694-697.

Scully, J.E.C. et al., 2013. Gullies on Vesta, related geologic features and possible formation mechanisms. Lunar Planet. Sci. 44, 1578-1579 (Abstracts).

Shinbrot, T. et al., 2004. Dry granular flows can generate surface features resembling those seen in martian gullies. Proc. Natl. Acad. Sci. 101, 8542-8546.

Shingareva, T.V., Kuzmin, R.O., 2001. Mass-wasting processes on the surface of Phobos. Solar Syst. Res. 35, 431-443.

Sierks, H. et al., 2011. The Dawn Framing Camera. Space Sci. Rev. 163, 263-327.

Singer, K.N. et al., 2012. Massive ice avalanches on lapetus mobilized by friction reduction during flash heating. Nat. Geosci. 5, 574-578.

Skinner Jr., J.A. et al., 2003. How should planetary map units be defined? In: Mackwell, S. (Ed.), Lunar Planetary Institute Science Conference Abstracts, vol. 34, pp. 2100.

Treiman, A.H., 2003. Geologic settings of martian gullies: Implications for their origins. J. Geophys. Res. - Planets 108, 1-13. 
U.S. Geological Survey, 2006. FGDC Digital Cartographic Standard for Geologic Map Symbolization. U.S. Geological Survey Techniques and Methods 11-A2. <http:// pubs.usgs.gov/tm/2006/11A02/>

Walsh, A.M. et al., 2003. Morphology and scaling of impact craters in granular media. Phys. Rev. Lett. 91, 1-4.
Wilhelms, D.E., 1990. Geologic mapping. In: Greeley, R. (Ed.), Planetary Mapping, pp. 208.

Williams, D.A. et al., 2013. Lobate and flow-like features on asteroid Vesta. Planet. Space Sci..

Yingst, R.A. et al., 2014. Geologic mapping of Vesta. Planet. Space Sci.. 